7. Garcia-Martin E, Rodriguez-Mena D, Herrero R, et al. Neuro-ophthalmologic evaluation, quality of life, and functional disability in patients with MS. Neurology 2013;81:76-83.

\section{SUMMARY OF EVIDENCE-BASED GUIDELINE UPDATE: PREVENTION OF STROKE IN NONVALVULAR ATRIAL FIBRILLATION: REPORT OF THE GUIDELINE DEVELOPMENT SUBCOMMITTEE OF THE AMERICAN ACADEMY OF NEUROLOGY}

Raul G. Lopez Valle, Houston: I read the most recent American Academy of Neurology guidelines regarding the prevention of stroke in nonvalvular atrial fibrillation. ${ }^{1}$ In the meta-regression of studies using continuous monitoring techniques, the authors reported a " $p$ value of less than 0.0000 ." This seems incorrect because a $p$ value cannot be smaller than zero or negative. The value of a " $p$ value" is that it is used to either reject or accept the null hypothesis, which indeed depends upon the $\alpha$ value set forth by the researchers. It is likely that the reported $p$ value does not represent a real zero, but it is small enough to reject the null hypothesis. I could not find the name of the software used to perform the metaregression and that is important, because the software used either cannot distinguish between the very small $p$ value and 0 or was not designed to provide a specific $p$ value when it is too small. Because a $p$ less than 0.000000001 will not indicate anything more than a $p$ less than 0.001 , a " $p$ less than 0.001 " will suffice.

Author Response: Gary Gronseth, Kansas City, KS: Regarding the $p$ value in our guideline, ${ }^{1}$ Dr. Lopez Valle is correct: the $p$ value referred to is not less than zero. The program used to perform the meta-regression calculates $p$ values to 4 digits of significance. The actual $p$ value is somewhere between zero and 0.00005 . The point, of course, is that the $p$ value is very small and the observed association is unlikely to be related to chance.

(C) 2014 American Academy of Neurology

1. Culebras A, Messé SR, Chaturvedi S, Kase CS, Gronseth G. Summary of evidence-based guideline update: Prevention of stroke in nonvalvular atrial fibrillation: report of the Guideline Development Subcommittee of the American Academy of Neurology. Neurology 2014;82:716-724.

\title{
CORRECTION
}

Sustained focal antitumor activity of bevacizumab in recurrent glioblastoma

In the article "Sustained focal antitumor activity of bevacizumab in recurrent glioblastoma" by O. Bähr et al. (Neurology ${ }^{\circledR}$ 2014;83:227-234), there is an error in the figure 2 legend, which should read: "Figure 2A shows the overall survival of patients without (black line) and patients with lesions with (red line, DWI/ADC) restricted diffusion. 2B shows overall survival of patients without (black line) and patients with (red line, T1) T1-hyperintense lesions. 2C shows overall survival of patients without (black line) and patients with (red line) 'double-positive' lesions. Tick marks indicate the time of patient censoring." The editorial staff regrets the error. 


\section{Neurology}

\section{Sustained focal antitumor activity of bevacizumab in recurrent glioblastoma Neurology 2014;83;1123 \\ DOI 10.1212/WNL.0000000000000853}

This information is current as of September 15, 2014

\section{Updated Information \&}

Services

Permissions \& Licensing

\section{Reprints}

including high resolution figures, can be found at: http://n.neurology.org/content/83/12/1123.2.full

Information about reproducing this article in parts (figures,tables) or in its entirety can be found online at:

http://www.neurology.org/about/about_the_journal\#permissions

Information about ordering reprints can be found online:

http://n.neurology.org/subscribers/advertise

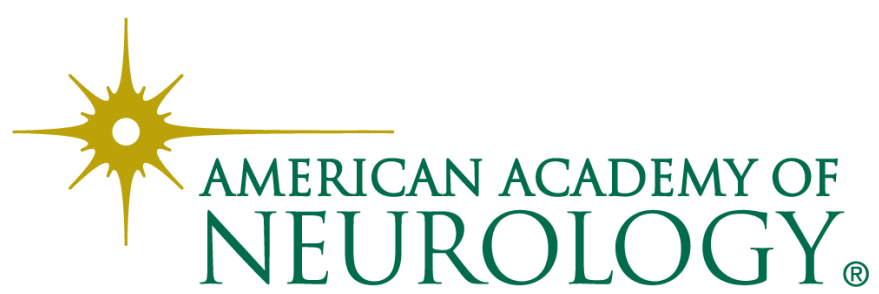

